\title{
Effect of oral exposure to the acaricide pirimicarb, a new varroacide candidate, on apis mellifera feeding rate
}

\author{
Riva Clémence ${ }^{1}$, Sokolowski Michel ${ }^{2}$, Normand Julien ${ }^{3}$, Sopkova-De Oliveira Santos Jana ${ }^{1}$, \\ Halm-Lemeille Marie-Pierre ${ }^{1,3, *}$
}

${ }^{1}$ UNICAEN, CERMN (Centre d'Etudes et de Recherche sur le Médicament de Normandie, EA 4258, FR CNRS 3038 INC3M - SF 4206 ICORE, Université de Caen Basse - Normandie, U.F.R. des Sciences Pharmaceutiques); 14032 Caen France

2 UPJV, GRAP (Groupe de Recherche sur l'Alcool et les Pharmacodépendances), Université de Picardie - Jules Verne, INSERM ERI24; 80025 Amiens France

${ }^{3}$ Ifremer Port-en-Bessin, Laboratoire Environnement Ressources de Normandie, 14520 Port-en-Bessin; France

* Corresponding author : Marie-Pierre, Halm-Lemeille, email address : marie.pierre.halm.lemeille@ifremer.fr

\begin{abstract}
:
BACKGROUND

The ectoparasitic honey bee mite Varroa destructor is one of the main causes related to the gradual decline of honey bees Apis mellifera. Nowadays, beekeepers utilize a wide range of different synthetic acaricides, organic acids and essential oils to keep mite populations under control. A previous work had shown that pirimicarb could be a new varroacide candidate. The aim of this study was to observe the chronic effects on worker honey bees feeding activity after an oral exposure to $1.05 \mathrm{mM}$ of pirimicarb. Long-term effect of a 24 hours exposition to pirimicarb were also tested.
\end{abstract}

\section{RESULTS}

After three successive trials were performed, no mortality could be detected at the tested concentration, oral exposure to pirimicarb had significant effect on honey bees feeding behavior. Pirimicarb added to a sucrose solution led to a rapid decrease of food intake. These tendencies may be reversed when the pesticide is removed. However, the recovery seemed to be trial-dependent.

\section{CONCLUSION}

The study highlights a seasonal variation of honey bee's susceptibility which should be considered in toxicology studies in general. 
Keywords : Apis Mellifera, Varroa destructor management, acaricide, pirimicarb, acetylcholinesterase 


\section{INTRODUCTION:}

The honey bee is the predominant pollinator, essential for agricultural production. Apis mellifera (Linnaeus, 1758) also provides pollination services to many wild plants. When foods that indirectly benefit from pollination are included, $35 \%$ of the human diet benefit from animal pollination [1]. Survey data indicate that the average winter mortality of colonies worldwide are well above the historical $10 \%$ considered by beekeepers as acceptable winter attrition [2-6]. Beekeepers not only lose colonies in the winter, but also throughout summer time, with variability within countries and regions. Interactions between multiple drivers are the most probable explanation for elevated mortality in honey bee colonies. Among these drivers, the parasitic mite Varroa destructor (Anderson and Trueman, 2000; formerly known as Varroa jacobsoni [7]), is the most detrimental honey bee parasite in the world today [8]. This mite is an obligatory parasite, spending its entire life in bee colony, either on immature stages or on adult bees [9]. The original varroa host is the Asian honey bee Apis cerana F. Host shift likely happened in the first half of the twentieth century, when Apis mellifera L. colonies were transported to Eastern Russia [10]. Since then, the mite has spread to all inhabited continents except Australia. Varroa destructor is widely considered to be a key player for honey bee colonies losses [11, 12]. Infested colonies develop the parasitic mite syndrome, or varroosis, which impairs both brood and adult bees [13]. If left untreated, colonies in temperate climates may die within one to three years after the initial infestation $[14,15]$. Nowadays, beekeepers use a wide range of methods to keep mite populations under control. Techniques can be biotechnical or chemical, with various application techniques [8]. The varroacides used can be broadly divided into three categories: synthetic organic compounds, natural products and organic acid pesticides [16]. In order to increase the treatments efficiency and to avoid resistance, various treatments with diverse mode of action should be combined [8]. However, limited economic resources are allocated to the search of new selective miticides. In this context, a "pesticide repositioning" approach was followed and highlighted pirimicarb as a new varroacide candidate [17].

Pirimicarb - [2-(dimethylamino)-5,6-dimethylpyrimidin-4-yl] N,N-dimethylcarbamate] is an N-methyl carbamate. Pirimicarb is included in group 1A of the IRAC (Insecticide Resistance Action Committee) mode of action classification scheme (www.iraconline.org), as an AChE inhibitor. Carbamates are employed as insecticides as they act as nerve poisons, causing a reversible carbamylation of acetylcholinesterase (AChE) [18, 19]. The carbamylated enzyme is a million-fold more stable than the acetylated enzyme transitorily produced during the hydrolysis of ACh [20]. The resulting inhibition of AChE produces a deadly accumulation of ACh at the synaptic junctions. As a carbamate compound, pirimicarbe shares a similar mode of action with the organophosphate coumaphos. Coumaphos is already known to be effective in controlling mites [21] and pirimicarb would answer to the need to diversify treatment mode of action in countries where coumaphos is not applied. Pirimicarb is use as a fast-acting selective aphicide on a 
wide range of crops including cereals, sugar beet, potatoes, fruits and vegetables. In addition, this pesticide is referenced in Tomlin's Pesticide Manual as an acaricide [22]. In their earlier paper, Dulin and collaborators (2014) have shown an in vitro inhibition of varroa AChE by pirimicarb (IC50: $6.6 \mu \mathrm{M}$ ), and little activity toward honey bees AChE has been observed in vivo after 24 hours of contact exposition to $1.05 \mathrm{mM}$ (dose corresponding to the contact LD50 for honey bee, divided by a factor 100) leading the authors to propose it as a new varroacide. The aim of this study is to obtain a better knowledge of the long-term effect of pirimicarb on honey bee health before proposing it as a new varroacide. Pirimicarb is a categorized as moderately toxic for the honey bee [23]. Dorsal thoracic application of pirimicarb induces a decrease in honey bee AChE activity [24]. Pirimicarb $\log \mathrm{P}$ is 1.7 , so it is not expected to accumulate in hives products such as wax and propolis, but may be transferred into honey. Garcia et al., report no side effects on the feeding behavior of ladybugs Semiadalia undecimnotata Schneider following treatment with pirimicarb [25].

In this study, we thus focused on pirimicarb ingestion consequences. Experiments were carried out at $1.05 \mathrm{mM}$, the effective concentration against varroa. This concentration of $1.05 \mathrm{mM}$ would be a worst-case scenario through a complete transfer of the active compound in honey. An administration in sugar-water trickle formulation could be considered. Honey bees may directly ingest the pirimicarb mixture at ideal concentration for a varroacide action. Various stress may induce variations in honey bees' feeding behavior, which is closely linked to insect health. For example, both parasitic microsporidia Nosema ceranae and Nosema apis [26], as well as the sublethal exposition to some herbicides [27] increased sugar syrup consumption. In a previous three days experiment (unpublished work), we observed a decrease in the honey bees' food consumption when pirimicarb was added to sugar. During these 72 hours, the first 24 hours were dedicated to an acclimation phase, and the remaining 48 hours were used to expose honey bees to the pesticide. In the present study, we pursue our previous works by studying pirimicarb effect over a longer period. Reasons of the decreasing food intake

will discuss through three main hypotheses: i) pirimicarb has an anti-feedant action or ii) pirimicarb is linked to a food aversion mechanism iii) pirimicarb has a neurotoxicity action. The hypothesis that, when pirimicarb is removed from the food, consumption will revert back to normal was also tested.

\section{MATERIALS AND METHODS}

\subsection{Honey bees}

Experiments were carried out using worker bees (Apis mellifera L.) of an undefined age. The whole hive population is concerned by an acaricide treatments, so it did not appear relevant to use honey bees of a particular age group in this experiment. Honey bees were collected in the afternoon, on brood combs from an outdoor hive. The hive was free from clinical symptom of disease. Bees were gently brush into a ventilated transparent container. Twenty bees were randomly introduced in each cage without any anesthesia, 
within 30 minutes after collection. Experiments were carried at room temperature, in a ventilated laboratory.

\subsection{Chemicals}

Bees were provided ad libitum a 50\% (weight/volume) sucrose solution made by dissolving refined table sugar in water. Pirimicarb of technical grade was obtained from Sigma-Aldrich and was dissolved in DMSO (Sigma-Aldrich). Syrup was added so the final pirimicarb concentration was $1.05 \mathrm{mM}$ and final DMSO concentration was $0.5 \%$. Treatments without pesticide were given a $50 \%$ sucrose solution containing $0.5 \%$ DMSO. Preliminary experiments have been performed to ensure that the chosen drug concentration induces no significant mortality. All solutions were replaced daily and kept in aluminum foil to avoid light degradation.

\subsection{Cages}

The cages used for this experiment are a laboratory version developed from a free flight devise previously described [28]. The internal size of cages was $20 \mathrm{~cm} \times 10 \mathrm{~cm} \times 9.5 \mathrm{~cm}$ (LxlxH). Cages were made of transparent PVC (sides), polystyrene (top) and of opaque white polycarbonate for the floor. Each cage has thirty-two $3.5 \mathrm{~mm}$ diameter breathing holes. Each cage was equipped with an automatic feeder that consisted of a $50 \mathrm{~mm}$ diameter polyamide disk with a centrally drilled hole (diameter: $6 \mathrm{~mm}$, depth: $17 \mathrm{~mm}$ ). The hole was fitted with an infrared sensor. For each honey bee visit, syrup was dispensed in the bottom of the hole with a dosing pump and through a $0.41 \mathrm{~mm}$ diameter needle. The maximum dispensed volume was $2 \mu \mathrm{L}$. The distribution of another $2 \mu \mathrm{L}$ required the honey bee to exit and re-enter into the hole.

Data were recorded on a micro-SD card and the experimental process management was automatically performed by a microcontroller (P8X32A) equipped with a real-time clock. To measure the consumption per living honey bees, each cage was topped with a photographic sensor (ref ADA397, 640x480 pixels) framing the cage floor. A picture was automatically taken every hour, and dead honey bees remove from the cages. Pictures were stored on a SD card piloted by a microcontroller board Arduino Uno.

A battery of twelve cages was running in parallel. At the end of each trial, silicon tubes of the pumps were purged and cleaned. A photoperiod control system was used to provide honey bees with fourteen hours of continuous daylight and ten hours of darkness.

\subsection{Experimental design}

All honey bees were left for 24 hours in cages for acclimatization. This period is considered as day zero (Fig 1) and will not consider it in our data analysis. Treatments were coded using the three following values: 
- "Control": for the cages where honey bees were only fed with sucrose solution throughout the trial.

- "Pirimicarb" where sucrose syrup with pirimicarb was given to honey bees, from the $2^{\text {nd }}$ day to the end of the experiment.

- " "Removal" where honey bees were fed with pirimicarb-containing syrup only during 24 hours on the second day, then back to sucrose solution.

These experiments were composed of three consecutive trials. The first trial was carried out from August 17 to 26, 2016, the second trial from August 28 to September 6, 2016; and the third one from the September 8 to 17, 2016.

\subsection{Statistical analysis}

The experimental setup allowed us to describe honey bees' feeding activity using two different variables:

1. the number of visits per hour into the feeding chamber of each experimental cage

2. the volume of syrup consumed per hour.

The values of these two descriptors depend on the number of living bees in the boxes. Therefore, number of visits as well as syrup consumed volume was divided by the number of living bees per cage.

During the experiments, honey bees' feeding activity appeared highly periodical due to circadian memory and the alternation of night and day periods, which was controlled by an automatic timer. This timer was programmed so that illumination started at 07:00 am and stopped at 09:00 pm, over a 24-hour period. Number of visits and syrup consumption were mostly restricted to daylight period, increasing until midday then slowly diminishing until nighttime. In this study, we were primarily interested in the variation of feeding behaviour in response to treatments, which was expected to be detected by the variation of the magnitude of the periodic signal across experimental conditions. Circadian cycles added an extra-source of variation for feeding activity descriptors. Another step of data treatment was necessary before the evaluation of the treatments effects, and a periodic 'cyclic activity' variable to score the alternation of day and night in boxes was computed.

Cyclic activity was computed as $-\cos \left(\frac{x \pi}{7}\right)$ from the values of $\mathrm{x}$ given below:

\begin{tabular}{|c|c|c|c|c|c|c|c|c|c|c|c|c|c|c|c|c|}
\hline \multirow{2}{*}{ Time } & $0 \mathrm{~h}-$ & $7 \mathrm{~h}-$ & $8 \mathrm{~h}-$ & $9 \mathrm{~h}-$ & $10 \mathrm{~h}-$ & $11 \mathrm{~h}-$ & $12 \mathrm{~h}-$ & $13 \mathrm{~h}-$ & $14 \mathrm{~h}-$ & $15 \mathrm{~h}-$ & $16 \mathrm{~h}-$ & $17 \mathrm{~h}-$ & $18 \mathrm{~h}-$ & $19 \mathrm{~h}-$ & $20 \mathrm{~h}-$ & $21 \mathrm{~h}-$ \\
& $7 \mathrm{~h}$ & $8 \mathrm{~h}$ & $9 \mathrm{~h}$ & $10 \mathrm{~h}$ & $11 \mathrm{~h}$ & $12 \mathrm{~h}$ & $13 \mathrm{~h}$ & $14 \mathrm{~h}$ & $15 \mathrm{~h}$ & $16 \mathrm{~h}$ & $17 \mathrm{~h}$ & $18 \mathrm{~h}$ & $19 \mathrm{~h}$ & $20 \mathrm{~h}$ & $21 \mathrm{~h}$ & $24 \mathrm{~h}$ \\
\hline $\mathrm{x}$ & 0 & 1 & 2 & 3 & 4 & 5 & 6 & 7 & 7 & 6 & 5 & 4 & 3 & 2 & 1 & 0 \\
\hline
\end{tabular}


Figure 2 presents an illustration of the cyclic activity computed values plotted against the observed syrup consumption values.

The number of visits, and syrup consumption, were regressed against the cyclic activity variable, in an attempt to recover residuals corrected for circadian circles. Due to the fact that the number of visits and syrup consumption were expressed on a "per hour" basis, that cyclic activity was considered an 8 level categorical variable. Syrup consumption and number of visits were also divided by the number of living bees, which rendered them discontinuous. Thus, generalized linear models were employed (instead of linear models), using quasi-Poisson distribution for errors, and a log-link function. For both variables of interest, the effects of cyclic activity appeared highly significant (for syrup consumption: $\chi^{2}{ }_{7.6509}=1301.2 ; \operatorname{Pr}\left[>\chi^{2}\right]<0.0001$; for the number of visits: $\chi^{2}{ }_{7.6373}=$ 849.74; $\left.\operatorname{Pr}\left[>\chi^{2}\right]<0.0001\right)$. The residuals were used as response variables in the following steps of analysis of data.

The second stage of the analysis was to study treatment effects on the residuals obtained previously. As expected for residuals, these data varied around 0. Positive values associated with any levels of treatment, or day $x$ treatment, characterized a feeding activity greater than the average for the population (in terms of syrup consumption or number of visits). Conversely, negative values were characteristic of a feeding activity lower than the population average. The three trials were considered as three independent block x treatment designs. Different boxes exposed to the same treatment constituted a block ( $\mathrm{n}=2$ blocks in the $1^{\text {st }}$ experiment, $\mathrm{n}=4$ blocks in the $2^{\text {nd }}$ and $3^{\text {rd }}$ experiments).

At this point, the aim was to evaluate the effects of a short-term exposure to pirimicarb on feeding activity descriptors, a condition that was reached for the "Removal" treatment condition, although "Pirimicarb" and "Syrup" could be considered as negative and positive controls. During the acclimatization period (the first 24 hours), all honey bees were fed with syrup (Figure 1). During the next 24 hours period, the food also consisted in syrup for "Syrup" control batch, but was replaced by syrup contaminated by pirimicarb for "Removal" and "Pirimicarb" treatment conditions. It was only at the end of the first 48 hours that the contaminated syrup was replaced by uncontaminated food in the "Removal" treatment's condition. Observations made during the first 48 hours period (from Day 0 to Day 2, see Figure 1) were deleted from the dataset. For each experiment, the linear model (Eq.1) was fitted to the data to estimate the effects of the treatments based on two response variables:

$$
Y=a \cdot \text { Treatment }+b
$$

A Fisher test was applied to compare the differences of feeding activity between treatments. 
Third and final stage of data analysis consisted of evaluating pirimicarb introduction, and its removal effects on feeding activity descriptors, focusing on potential recovery effects. For this purpose, only the observations made during the first 96 hours were kept, to cover the starting period (Day1) the impregnation period (Day2, when bees were fed with syrup contaminated with pirimicarb in the "removal" condition of treatment), and the next 48 hour period of observation when recovering was expected to occur (Figure 1). For each experiment, and for each response variable, the linear model (Eq.2) was fitted to the data

$$
Y=a \cdot \text { Treatment }+b \cdot \text { Day }+c \cdot(\text { Treatment } \times \text { Day })+d
$$

A Fisher test was used to check for overall treatment, day and interaction effects on feeding activity descriptors. Daily variation within treatment was compared using Fisher's protected least mean difference (LSD) at $\mathrm{P}=0.05$.

All analyses and figures were performed using the R software [29].

\section{RESULTS \& DISCUSSION}

As observed in this experiment, honey bees had a circadian rhythm of feeding activity (Figure 2). Spangler (1972) measured the locomotor activity of individually isolated honey bees and found that circadian rhythms are absent in younger worker bees (in the cell-cleaning and nursing phases) but present in forager bees [30]. Newly emerged worker honey bees are initially arrhythmic, but they gain rhythmicity and become diurnal during behavioral development [31]. There is also an endogenous circadian rhythms in metabolic activity of workers, measured through oxygen consumption [32]. The feeding activity in the present experiment follows a similar rhythmicity.

\subsection{Observed Survival from Treatments}

The treatment period with pirimicarb did not lead to additional mortality (Error! Reference source not found.). Control mortalities were 32, 15, and $7 \%$ at the end of the three experiments respectively. In each trial, no significant results were found when the survival of dosed bees was compared to their respective control group after 10 days of experiment. On average, a survivabilty gap of $6 \%$ was observed between "Control" and "Pirimicarb" or between "Control" and "Removal" groups. Moreover, during all treatment, no neurotoxic symptoms such as trembling and paralysis were observed for honey bees.

\subsection{Chronic Effects}


Figure 3 gives global indications on the chronic effects after a short-term exposure to pirimicarb. Each bar graph represents feeding behavior data from the third day to the end of each trial.

Table 2 gives the results associated to Fisher's test on residuals. A significant effect (pvalue $<0.05$ ) of the treatment was observed for the two variables (i.e the consumption of syrup and the number of visits to the feeding hole). Continuous exposure to pirimicarb was associated with negatives residuals. This decline was smaller for a 24 hours exposure (see "Removal" group in Figure 3). Results suggest a variation between the three trials, therefore trials were considered separately. Across all control groups, the daily mean syrup consumed per bee was determined to be $23 \mu \mathrm{L}$ per day. Within the pirimicarb treatment, the daily means of contaminated syrup consumed per bee were 20 , $10,13 \mu \mathrm{L}$ for each trial respectively. The daily means of pirimicarb consumed per bee was approximately $3.6 \mu \mathrm{g}$. The absence of difference in survival rates in our experiment seems to disagree with the oral LD50 established at 3,8 $\mu \mathrm{g} / \mathrm{bee}$ [22].

The information provided by the two variables was quite redundant, so focus will be on the syrup consumption for further analysis.

\subsection{Recovery After 24 Hours of Exposition to Pirimicarb}

This section focuses on the potential recovery after the oral exposure to pirimicarb. Results for the daily food consumption ( $\mu \mathrm{L} /$ hour), in relation to the number of living honey bees, are shown in Figures 4.

The volume of consumed syrup per hour remained stable for the "control" group. A slight decrease in syrup consumption can be observed on the second day of the first trial (Figure 4.1.A), with no apparent reason. Pirimicarb has caused a drastic reduction of syrup consumption in the two-last trials (Figures 4.2.B and 4.3.B). This variation was weaker during the first trial (Figure 4.1.B) where the consumption had not a significant downward trend. After this drop, the variables remained at a constant low level, with slight variation but without clear decline or improvement. The same reduction can be seen for the "Removal" groups when pirimicarb was introduced in the syrup only 24 hours on Day 2.

Results show a complete recovery regarding honey bees' feeding behavior on Day 4 of the first trial (Figure 4.1.C). Recovery of honey bees in the second trial seemed uncertain (Figure 4.2.C) and syrup consumption stayed instable. There was no complete recovery of the variable on the third trial (Figure 4.3.C). The three successive trials demonstrate a temporal variability in honey bees' response pattern to pirimicarb. Circadian and seasonal changes in the susceptibility of honey bee workers to intoxication by pirimicarb have been previously investigated [33]. It was shown that the time of day and season in which contact of the honey bees with pirimicarb occurs determines its toxic effect. The study highlighted that, in most cases, the honey bees intoxicated by contact in the spring were characterized by higher survival rate than those treated by the insecticide in the summer. According to IRAC, resistance to insecticides can be due to metabolic 
resistance, alterations in the insecticide target site that lower binding or the insecticide effector function, to penetration resistance or to behavioral resistance. In the situation of seasonal resistance variations, metabolic changes are the most probable. Honey bees are subjected to seasonal physiological changes that include, among others, changes in neurotransmitter levels, protein metabolism, juvenile hormone titers, blood sugar concentrations, oxidative metabolism and behavior [34-38]. All these seasonal variations may modify their susceptibility to toxic compounds $[38,39]$. There is, in the fat body of the fruit fly, a rhythmic expression of genes related to metabolism and the detoxification system (including cytochrome P450 and oxidoreductase genes) which may be involved in diurnal changes in the resistance against insecticides [40]. In addition, 'winter honey bees' workers, reared during late summer, have greater investment in fat bodies and other physiological differences, allowing them to overwinter in the hive for up to 6 months $[34,36]$. In our experiment, the first trial started on August 17, while the third one started on September 8, 2016. In less than a month, drastic variations are not expected, but the transition to winter physiology could already be initiated due to the local climate of north of France where experiments took place.

Continuous exposure to sub-lethal doses to the AChE inhibitor pesticide pirimicarb altered honey bee feeding behavior. Several hypotheses could explain this sub-lethal effect.

The ability to identify food that is nutrient-rich and to avoid toxic substances is essential for survival. Learned food avoidances may arise from two independent reinforcement pathways: either by association of an odor with a reflexive taste aversion toward a toxin, or by association of an odor with the malaise caused by toxin ingestion [41]. It was reported that the honey bee has only ten gustatory receptors [42] and thus may have a very poor taste perception compared to Drosophila, which presents 68 gustatory receptors [43-45]. However, several arguments are in favor of a gustatory receptor repertoire that could be more complex than what has been proposed [46]. Avoidance of a bad-tasting toxins should lead to a quick recovery, which was not observed in our study. The lack of recovery during the second and the third trial argues against the anti-feedant activity. The delay in the recovery process is more consistent with the second pathway where honey bees learn to associate a gustatory cue with the postingestive consequences of eating a toxin associated with it [41]. However, no abnormal intestinal activity was observed in the exposed groups, through the quantity, aspect and color of honey bee feces, in the exposed groups. Behavior differences between the three trials are not in agreement with the postingestive consequences pathway.

The last hypothesis is linked to potential neurotoxic activities of pirimicarb. The observed feeding behavior modifications may be physiological consequences of AChE's inhibition by a carbamate. Previous work has shown that continuous exposure, through a sucrose solution, with AChE inhibitors for 24 hours, affected the walking behavior, notably increased honey bees' grooming activity and increased $\mathrm{AChE}$ gene transcription in the brain and the gut [47]. Unfortunately, we were unable to measure the AChE activity or gene expression in our experiment. In vitro comparison of inhibition kinects 
of purified AChE from emerging and foraging honey bees showed that the enzyme from foragers is more susceptible to this insecticide than the emerging honey bees' [48]. Reversibility of effects, or not, relies on the age of worker honey bees and the annual period of exposition.

New varroacide should aim at the best performance and cost-benefit relation. To recommend pirimicarb as a new treatment, additional research will have to ensure that the decreased food intake will not penalize the colony development; toxic effects of pirimicarb should be modulated thanks to appropriate galenic formulation. There is a trade-off between energy acquisition and activation of the insect's immune system to fight infections [49]. Short-term food deprivation in insects leads to a downregulation of the immune system, resulting in a weaker resistance when challenged with infection. When fed under ideal conditions, the immune system is restored [50]. Energy stress has a major impact on the success of bee foraging since carbohydrates are their main source of fuel for flight, and foraging is a metabolically expensive activity [51]. It is important to note that energy stress was observed in bees maintained under laboratory conditions, while under natural conditions, a combination of other factors may represent additional negative influences on honey bees.

\section{CONCLUSION}

By far the most important contributor in pollination service, the honey bee has a crucial role for agricultural production. In the attempt to protect honey bees against one of its major threat, we have studied the consequences of an oral exposure to the carbamate pirimicarb, a varroacide candidate. Pirimicarb probably had sub-lethal but toxic effect on honey bees, leading to an observed food-intake decrease. This effect was weaker in the first trial, suggesting a real impact of the exposition period. A decreased food-intake may be responsible for an energy stress. Therefore, future research is needed to evaluate the cost-benefit relation associated with pirimicarb use, before recommending this carbamate as a varroa control product. In a more general perspective, honey bees' feeding activity variable may be considered while studying other varroacides side-effects on honey bees.

\section{ACKNOWLEDGEMENTS}

Acknowledgments are due to Lorraine Chambry for technical support, and to Florian Lamousse, for the illustration use in the graphical abstract of this article.

\section{REFERENCES}

1. Klein AM, Vaissiere B., Cane J., Steffan-Dewenter I, Cunningham SA, Kremen C, Tscharntke $\mathrm{T}$ (2007) Importance of pollinators in changing landscapes for world crops. Proc R Soc Lond B Biol Sci 274:303-313

2. Lee KV, Steinhauer N, Rennich K, Wilson ME, Tarpy DR, Caron DM, Rose R, Delaplane KS, Baylis K, Lengerich EJ (2015) A national survey of managed honey bee 2013-2014 annual colony losses in the USA. Apidologie 46:292-305 
3. Chauzat M-P, Laurent M, Rivière MP, Saugeon C, Hendrikx P, Ribière-Chabert M (2014) A pan-European epidemiological study on honey bee colony losses 2012-2013. Eur. Union Ref. Lab. Honeybee Health Bruss. Rapp. Tech.

4. Spleen AM, Lengerich EJ, Rennich K, Caron D, Rose R, Pettis JS, Henson M, Wilkes JT, Wilson M, Stitzinger J (2013) A national survey of managed honey bee 2011-12 winter colony losses in the United States: results from the Bee Informed Partnership. J Apic Res 52:44-53

5. Brodschneider R, Gray A, van der Zee R, Adjlane N, Brusbardis V, Charrière JD, Chlebo R, Coffey MF, Crailsheim K, Dahle B (2016) Preliminary analysis of loss rates of honey bee colonies during winter 2015/16 from the COLOSS survey. J Apic Res 55:375-378

6. Van der Zee R, Pisa L, Andonov S, Brodschneider R, Charriere JD, Chlebo R, Coffey MF, Crailsheim K, Dahle B, Gajda A (2012) Managed honey bee colony losses in Canada, China, Europe, Israel and Turkey, for the winters of 2008-9 and 2009-10. J Apic Res 51:100-114

7. Anderson DL, Trueman JWH (2000) Varroa jacobsoni (Acari: Varroidae) is more than one species. Exp Appl Acarol 24:165-189

8. Rosenkranz P, Aumeier P, Ziegelmann B (2010) Biology and control of Varroa destructor. J Invertebr Pathol 103:S96-S119

9. Nazzi F, Le Conte Y (2016) Ecology of Varroa destructor, the major ectoparasite of the western honey bee, Apis mellifera. Annu Rev Entomol 61:417-432

10. Oldroyd BP (1999) Coevolution while you wait: Varroa jacobsoni, a new parasite of western honeybees. Trends Ecol Evol 14:312-315

11. Dahle B (2010) The role of Varroa destructor for honey bee colony losses in Norway. J Apic Res 49:124-125

12. Dainat B, Evans JD, Chen YP, Gauthier L, Neumann P (2012) Predictive markers of honey bee colony collapse. PLoS One 7:e32151

13. Shimanuki H, Calderone NW, Knox DA (1994) Parasitic mite syndrome: the symptoms. Am Bee J 134:827-828

14. Boecking O, Genersch E (2008) Varroosis-the ongoing crisis in bee keeping. J Für Verbraucherschutz Leb 3:221-228

15. Büchler R (1994) Varroa tolerance in honey bees - occurrence, characters and breeding. Bee World 75:54-70

16. Johnson RM, Ellis MD, Mullin CA, Frazier M (2010) Pesticides and honey bee toxicity-USA. Apidologie 41:312-331

17. Dulin F, Zatylny-Gaudin C, Ballandonne C, Guillet B, Bonafos R, Bureau R, Halm M-P (2014) Protecting honey bees: identification of a new varroacide by in silico, in vitro, and in vivo studies. Parasitol Res 113:4601-4610

18. Fukuto TR (1990) Mechanism of action of organophosphorus and carbamate insecticides. Environ Health Perspect 87:245-254

19. Main AR (1979) Mode of action of anticholinesterases. Pharmacol Ther 6:579-628 
20. Metcalf RL (1971) Session I-The Inhibition of Esterases by Organophosphorus Compounds and Carbamates: Structure - activity relationships for insecticidal carbamates. Bull World Health Organ 44:43

21. Elzen P, Baxter J, Spivak M, Wilson W (2000) Control of Varroa jacobsoni Oud. resistant to fluvalinate and amitraz using coumaphos. Apidologie 31:437-441

22. Tomlin C (1994) The pesticide manual. British Crop Protection Council, Surrey, UK

23. Kegley SE, Hill BR, Orme S, Choi AH (2016) Pan Pesticide Database, Pesticide Action Network.

24. Badiou A, Meled M, Belzunces LP (2008) Honeybee Apis mellifera acetylcholinesterase - a biomarker to detect deltamethrin exposure. Ecotoxicol Environ Saf 69:246-253

25. Garcia V, Ferran A, Larroque M-M (1981) Effets secondaires d'un insecticide, le pyrimicarbe, sur la physiologie alimentaire des larves âgées de la coccinelle aphidiphage Semiadalia undecimnotata Schneider (Col. Coccinellidae). Agronomie 1:413-418

26. Martín-Hernández R, Botías C, Barrios L, Martínez-Salvador A, Meana A, Mayack C, Higes M (2011) Comparison of the energetic stress associated with experimental Nosema ceranae and Nosema apis infection of honeybees (Apis mellifera). Parasitol Res 109:605-612

27. Helmer SH, Kerbaol A, Aras P, Jumarie C, Boily M (2015) Effects of realistic doses of atrazine, metolachlor, and glyphosate on lipid peroxidation and diet-derived antioxidants in caged honey bees (Apis mellifera). Environ Sci Pollut Res 22:8010-8021

28. Sokolowski MBC, Abramson CI (2010) From foraging to operant conditioning: A new computer-controlled Skinner box to study free-flying nectar gathering behavior in bees. J Neurosci Methods 188:235-242

29. RC Team (2015) R: A language and environment for statistical computing. R Foundation for Statistical Computing, Vienna, Austria.

30. Spangler HG (1972) Daily activity rhythms of individual worker and drone honey bees. Ann Entomol Soc Am 65:1073-1076

31. Moore D (2001) Honey bee circadian clocks: behavioral control from individual workers to whole-colony rhythms. J Insect Physiol 47:843-857

32. Southwick E, Moritz R (1987) Social synchronization of circadian rhythms of metabolism in honeybees (Apis mellifera). Physiol Entomol 12:209-212

33. Piechowicz B, Grodzicki P, Stawarczyk M, Stawarczyk K (2013) Circadian and seasonal changes in the honeybee (Apis mellifera) workers susceptibility to diazinon, teflubenzuron, pirimicarb and indoxacarb. Pol J Env Stud 22:1457

34. Fluri P, Lüscher M, Wille H, Gerig L (1982) Changes in weight of the pharyngeal gland and haemolymph titres of juvenile hormone, protein and vitellogenin in worker honey bees. J Insect Physiol 28:61-68

35. Harris JW, Woodring J (1992) Effects of stress, age, season, and source colony on levels of octopamine, dopamine and serotonin in the honey bee (Apis mellifera L.) brain. J Insect Physiol 38:29-35 
36. Kunert K, Crailsheim K (1988) Seasonal changes in carbohydrate, lipid and protein content in emerging worker honeybees and their mortality. J Apic Res 27:13-21

37. Shehata SM, Townsend GF, Shuel RW (1981) Seasonal physiological changes in queen and worker honeybees. J Apic Res 20:69-78

38. Smirle MJ, Winston ML (1987) Intercolony variation in pesticide detoxification by the honey bee (Hymenoptera: Apidae). J Econ Entomol 80:5-8

39. Meled M, Thrasyvoulou A, Belzunces LP (1998) Seasonal variations in susceptibility of Apis mellifera to the synergistic action of prochloraz and deltamethrin. Environ Toxicol Chem $17: 2517-2520$

40. Xu K, DiAngelo JR, Hughes ME, Hogenesch JB, Sehgal A (2011) Interaction between circadian clocks and metabolic physiology: implications for reproductive fitness. Cell Metab 13:639

41. Wright GA, Mustard JA, Simcock N, Ross-Taylor AR, McNicholas LD, Popescu A, MarionPoll F (2010) Parallel reinforcement pathways for conditioned food aversions in the honeybee. Curr Biol 20:2234-2240

42. Robertson HM, Wanner KW (2006) The chemoreceptor superfamily in the honey bee, Apis mellifera: expansion of the odorant, but not gustatory, receptor family. Genome Res 16:13951403

43. Scott K, Brady R, Cravchik A, Morozov P, Rzhetsky A, Zuker C, Axel R (2001) A chemosensory gene family encoding candidate gustatory and olfactory receptors in Drosophila. Cell 104:661-673

44. Robertson HM, Warr CG, Carlson JR (2003) Molecular evolution of the insect chemoreceptor gene superfamily in Drosophila melanogaster. Proc Natl Acad Sci 100:14537-14542

45. Clyne PJ, Warr CG, Carlson JR (2000) Candidate taste receptors in Drosophila. Science 287:1830-1834

46. de Brito Sanchez G, Ortigao-Farias JR, Gauthier M, Liu F, Giurfa M (2007) Taste perception in honeybees: just a taste of honey? Arthropod-Plant Interact 1:69-76

47. Williamson SM, Moffat C, Gomersall M, Saranzewa N, Connolly C, Wright GA (2013) Exposure to acetylcholinesterase inhibitors alters the physiology and motor function of honeybees. Front Physiol 4:13

48. Belzunces LP, Colin ME (1991) Differential response of Apis mellifera acetylcholinesterase towards pirimicarb. Neuroreport 2:265-268

49. Schmid-Hempel P (2005) Evolutionary ecology of insect immune defenses. Annu Rev Entomol 50:529-551

50. Siva-Jothy MT, Thompson JW (2002) Short-term nutrient deprivation affects immune function. Physiol Entomol 27:206-212

51. Rothe U, Nachtigall W (1989) Flight of the honey bee. J Comp Physiol [B] 158:739-749 


\section{FIGURE LEGENDS}

Fig 1. Protocol used for the three trials (timing and diet).

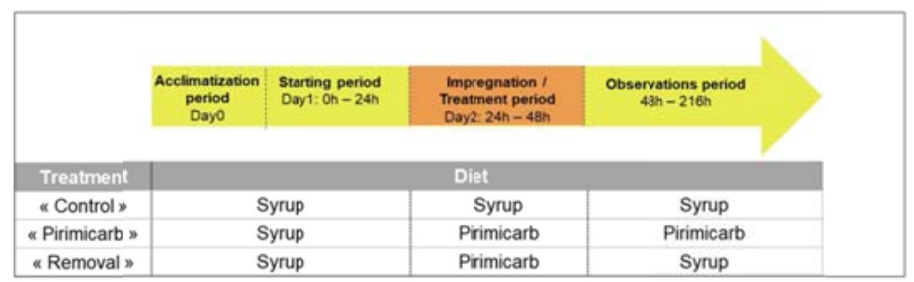

Fig 2. Variation across time and experiments of the observed syrup consumption per hour and per individual (gray rings). Computed theoretical variable describing cyclic activity is plotted on figure (continuous lines).

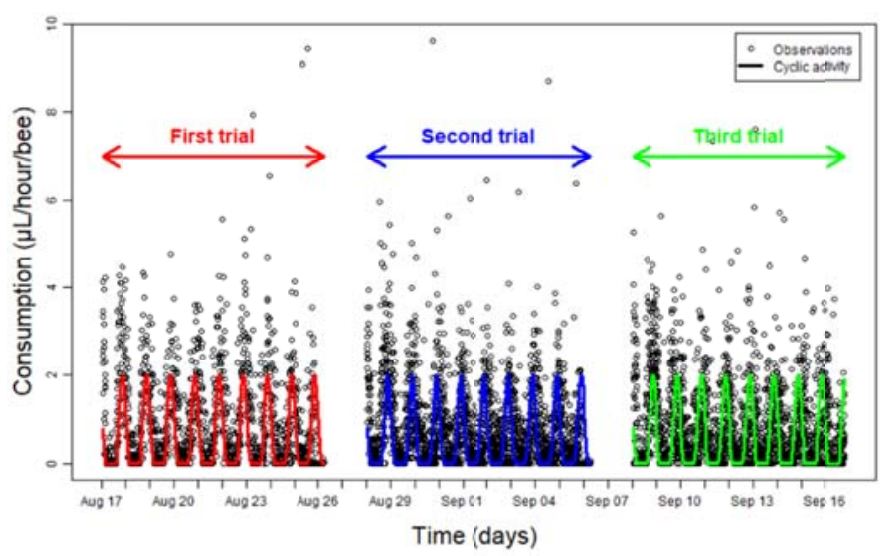

Fig 3. Treatment effects on the residuals for both feeding activity descriptors mean $( \pm s e) . A$, $B$ and $C$ stand for first, second and third trials respectively

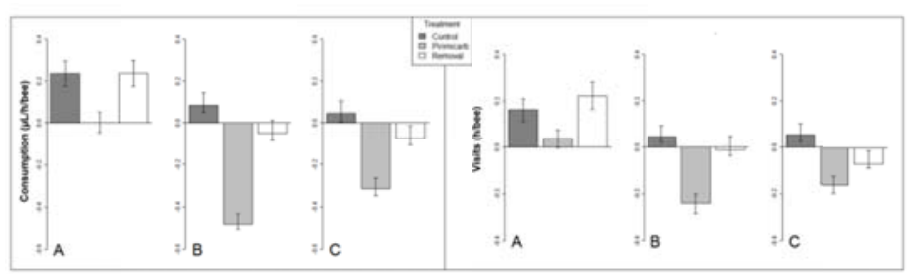

Fig 4. Bar graphs showing the residual syrup consumption (mean \pm se) during the first, the second and the third trials. D1,D2,D3 and D4 represent from the first to the fourth day of the experiment respectively. A: Control Treatment; B: Pirimicarb Treatment; C: Removal Treatment. Fisher tests $(P=0.05)$ were performed. Any treatments which were not significantly different from one another are illustrated as the same letter on the bar graph. 


\section{TABLE LEGENDS}

Table 1. Mean survival rate ( \pm se) in relation to treatment, df represents the degree of freedom of the test. The $p$ value associated with the $X^{2}$ is indicated.

Table 2. Results for Fisher's test applied to compare the differences of feeding activity between treatments (df: degrees of freedom, $p$ : $p$-value).

Table 1. Mean survival rate ( \pm se) in relation to treatment, $d f$ represents the degree of freedom of the test. The $\mathrm{p}$ value associated with the $\mathrm{X}^{2}$ is indicated.

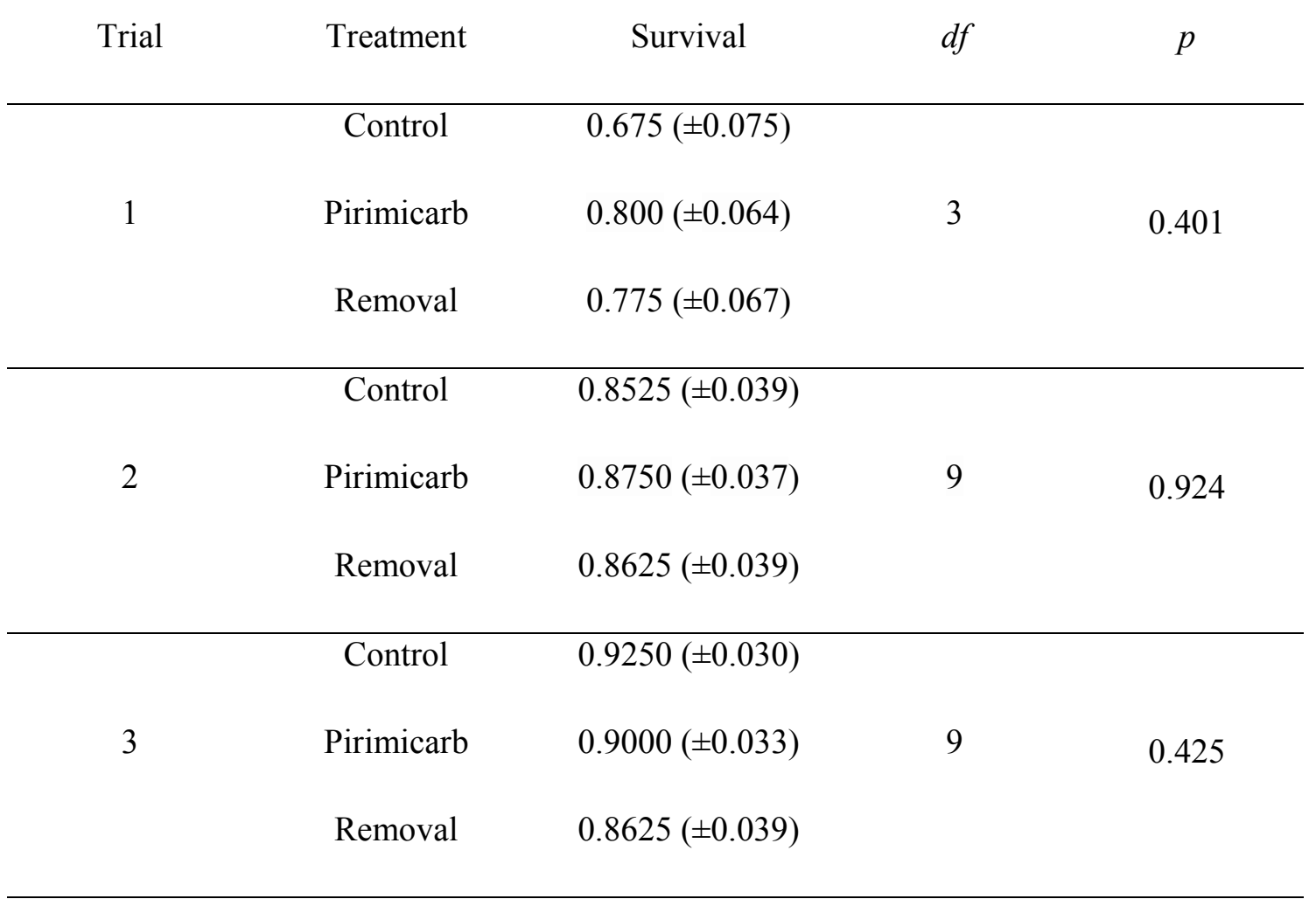

Table 2. Results for Fisher's test applied to compare the differences of feeding activity between treatments (df: degrees of freedom, $p$ : p-value). 
Consumption of syrup Number of visits

\begin{tabular}{ccccc}
\hline Trial & $d f$ & $p$ & $d f$ & $p$ \\
\hline 1 & 2 & 0.00363 & 2 & 0.0234 \\
2 & 2 & $<0.001$ & 2 & $<0.001$ \\
3 & 2 & $<0.001$ & 2 & $<0.001$ \\
\hline
\end{tabular}

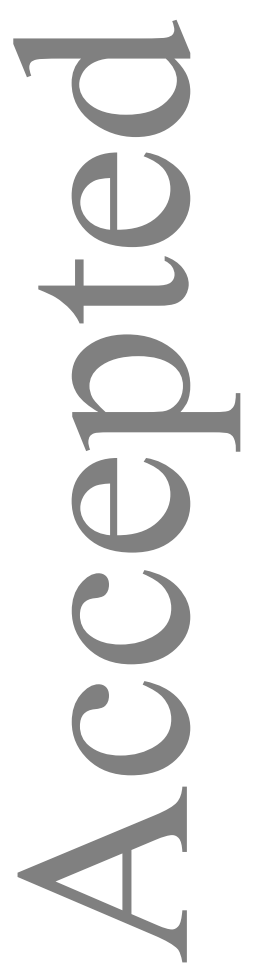

